\title{
SERVICE QUALITY IMPROVEMENT FOR SENIOR TOURISTS AT HOTELS AND RESORTS IN THE PERCEPTION OF SERVICE PROVIDERS: NAKHON RATCHASIMA, THAILAND
}

\author{
Thanasit Suksutdhi
}

\author{
Suan Sunandha Rajabhat University, Bangkok, Thailand
}

This research aims to investigate the perceptions of service quality improvement among the senior tourists staying in hotels and resorts of the Nakhon Ratchasima province. This qualitative research uses Parasuraman, Zeithaml and Berry's (1990) service quality model as a theoretical conceptual framework. The in-depth interview method was applied to collect data from five hotel and resort providers in Nakhon Ratchasima province of Thailand. Findings of the content analysis show that hotel and resort managers place great importance on all five dimensions of service quality: 1) Tangible assets, 2) Reliability, 3) Responsiveness, 4) Assurance, and 5) Empathy. Importantly, managers value front-line employees and safety because these are the key factors in attracting senior tourists to hotels and resorts. The findings of this study can be used as guidelines in further improvement of service quality which will benefit the hotel and resort operators as well as government agencies responsible for tourism and hospitality service development.

Keywords: tourist perceptions; service quality; senior tourists; hotel managers; hotels \& resorts; Thailand

\section{Introduction}

Advances in medical studies and public healthcare development have reduced the mortality rates across many countries and have also increased life expectancy, thus affecting the structure of population which is now stepping towards the so-called aging society. In Thailand in particular, the National Statistical Office (2019) showed that this country has been stepping into the category of aging societies since 2005 and thus the Office predicted that the share of Thai population aged $60+$ will increase up to $15.7 \%$ by 2030 . Such an

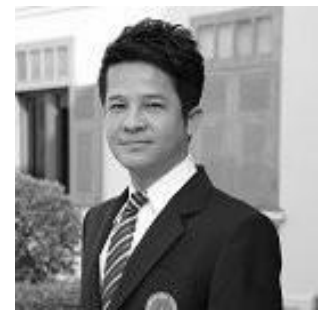

Thanasit Suksutdhi

Master of Arts in Cultural Management (International Program), Chulalongkorn University, Bangkok, Thailand.

Bachelor of Arts in Tourism Industry, Nakhon Ratchasima Rajabhat Institute, Thailand. Lecturer in Hotel Management (Restaurant Business Major), International College, Suan Sunandha Rajabhat University, Thailand.

Research interests: restaurant management, marketing in hospitality and restaurant business.

E-mail: tanasit.su@ssru.ac.th 
increase in the number of elderly consumers affects businesses across all sectors and sizes and makes them feel the need to be ready for corresponding changes.

After retirement, most of the elders are well-equipped with time and finances, both allowing them to spend their lives being engaged in various activities, especially leisure activities such as travelling. Therefore, we can surely state that the elders are a large group of quality tourists (Nella \& Christou, 2016).

The growth in the number of elderly tourists causes many hotels and travel companies to prepare special products for this prosperous target segment, known as "senior tourism" (Nikitina \& Vorontsova, 2015). Accordingly, the future of tourism and hotel industries strongly depends on identification of quality and variety of the services and products that are supposed to meet the needs of senior citizens. This will help tourism and hotel businesses prolong the tourism period, handle seasonality issues, increase job opportunities in the sector, and tackle other tourism management issues (Nella \& Christou, 2016).

Accommodation that is meeting special needs of senior tourists has thus become a priority for the tourism-related service industries, especially hotel businesses which directly contribute to tourists' traveling experiences. However, little empirical evidence has been presented to date on the evaluation of service quality in the hotel industry, especially from the perspective of service providers in Thailand. This research aims to investigate the hotels and resorts providers' perceptions of the service quality improvement for senior tourists in Nakhon Ratchasima, one of Thailand's most popular destinations, known as the gateway to the Northeast region (Tourism Authority of Thailand, 2019).

\section{Literature Review}

\section{Senior Tourism}

The exponential increase in the number of senior citizens globally has made them more demanding consumers. This rather promising tourist segment is approaching one fifth of the general population (Alén et al., 2012). Senior tourists group is composed of retired or not yet retired people, 55 years old or more, with different income levels who are mentally and physically self-sufficient and have enough time and financial resources for non-seasonal travel to various destination points (Alén et al., 2012).

The research shows that both external conditions (e.g., societal progress, time, health personal finance, attractions, facilities, activities, safety and security, cleanliness, etc.) as well as internal desires (novelty and knowledge seeking, rest and relaxation, well-being, escaping from routine, social and personal reward) motivate senior tourists, especially Asian ones (first of all Chinese, Taiwanese and Japanese), to visit various destinations (Jang \& Wu, 2006; Hsu et al., 2007; Sangpikul, 2008). Service providers in tourism-related industries need to tailor their offerings in response to different needs, values and concerns of senior tourists (Cleaver et al., 2000). Lack of interactions between tourists and service providers at the managerial level (with hotel managers) causes misunderstanding of tourists' needs, values and expectations (Tsang \& Qu, 2000). Therefore, it is critical for managers and service providers to understand the needs and expectations so that they can provide quality products and services that meet such expectations (Luk \& Layton, 2002). 


\section{SERVICE QUALITY IMPROVEMENT FOR SENIOR}

\section{Service Quality Model}

Many recent research studies on service quality have been adopting the framework of Parasuraman et al. (1990) service quality model which has five dimensions:

1. Reliability: the ability to provide the promised service to the client;

2. Assurance: the ability to build confidence by demonstrating knowledge and skills of service provision in response to clients' needs;

3. Responsiveness: the ability to provide attentive servicing and prompt reaction;

4. Empathy: the ability to attend service recipients thoroughly and provide attentive service considering the best interests of the serviced clients;

5. Tangibles: these include physical assets, personnel, facilities and environment in various locations, equipment, tools, documents and so on.

Service quality is importantly affecting the satisfaction level among the customers of hotel businesses (Thanakitputimed, 2016), especially senior travelers because of their special needs for extra care and safety facilities (Viwatkamolwat et al., 2017; Thammasane, 2012).

\section{Research Method and Data Analysis}

Using Parasuraman's et al. (1990) service quality model, this qualitative research investigates the hotel managers' perceptions of service quality improvement for senior tourists. An in-depth interview method was used to collect data from five senior hotel and resort managers in Nakhon Ratchasima province (Thailand).

Following Bengtsson's (2016) suggestions, this research has also employed qualitative content analysis to systematically analyze the obtained data in order to find meanings, themes or concepts of the managers' perceptions regarding service quality improvement in the hotel under their management and our investigation.

\section{Findings}

In total, five senior managers of hotels and resorts in Nakhon Ratchasima province were participating in the interviews. The findings show that all the managers place importance on the improvement of service quality in five dimensions: 1) Tangible, 2) Reliability, 3) Responsiveness, 4) Assurance, and 5) Empathy. Below we describe the obtained findings in more detail, divided into these five dimensions.

\section{1) Tangible improvement}

Hotel and resort managers in Nakhon Ratchasima province have given great importance to the development and improvement of service quality in terms of tangible assets to support senior tourists and make a good impression on them. Most of the hotels are decorated in a modern style focusing on exotics and creativity. The hotels have also tried to convey more Thai culture in their decoration. Facilities in a hotel must be fully completed, so that the elderly can use all the facilities easily and conveniently. The findings also emphasize that managers are concerned about cleanliness, modesty and attire of their frontline service staff so that to make a great impression on the customers during their stay.

\section{2) Reliability improvement}

The image of a hotel is top priority in terms of reliability in the managers' perception. Since the vast majority of the elderly visitors are always concerned about safety, hotels and resorts must have a good image in what is known as zero crime level. Services provided by 
hotel staff is another factor that matters the most. It is very crucial that employees can serve customers accurately and can solve any emerging visitors' problems promptly. Only then the elderly customers will have trust in the hotel staff. This will improve visitors' perception of the hotels' reliability.

\section{3) Responsiveness improvement}

All the managers agreed that prompt response to the needs of elderly customers is a critical factor because it leads to repeated visits by senior tourists. Elderly customers want special care and on-time service. Therefore, hotels should always have a sufficient number of employees to meet these needs. The employees must have a service-oriented mindset as well as sufficient knowledge and skills for problem-solving. They must be both reliable and enthusiastic while responding to customers' needs. For example, multiple channels of rooms' reservation should be available to customers.

\section{4) Assurance improvement}

Most of the surveyed hotel managers focus on security because this factor will always give customers peace in mind. The feeling of security and safety is especially important for senior tourists because they need to be assured that once staying in this hotel, there will be absolute security throughout the stay. A hotel security system must fully comply with the world standards. Examples: the hotel must have security officers, there must be CCTV cameras working and so on.

\section{5) Empathy improvement}

Finally, the findings show that empathy is a relative challenge in part of service improvement in the perceptions of hotel and resort managers. Most of them value their employees because they have direct interactions with customers and thus, are an intermediary to impress customers, apart from the hotel/resort itself. Hotel employees must understand different needs of senior visitors and be able to serve these needs accordingly. They must pay attention to their manner of their greeting and manner of communication overall. Also, they must treat all the visitors equally and must not discriminate anyone.

\section{Discussion and Conclusion}

The findings of this qualitative research show that managers in the hotel business are aware of the potential of senior tourism considerably and thus are interested in continuous improvement of service quality to better serve this target group of tourists specifically. This finding is similar to the findings of Nella \& Christou's (2016) study on the extending tourism marketing in the senior tourism segment. Similar to previous research on the perceptions of managers in service quality (Tsang \& Qu, 2000), this research demonstrates that the five dimensions of Parasuraman's et al. (1990) service quality model can provide the insightful information on the service providers' perspective of service quality improvement.

Unlike the findings of Tsang \& Qu's (2000) study on service quality of the hotel industry in China, this research shows that the hotel and resort managers in Nakhon Ratchasima province understand very well the needs and expectations of senior tourists and thus put efforts to improve their service quality to match these needs and expectations. The managers place great importance on improving hotel facilities, assurance of both safety and security, staff reliability, responsiveness and empathy to better serve senior tourists. These findings are in accordance with the past research studies carried out by (Jang \& Wu, 2006; Hsu et al., 2007; Sangpikul, 2008) which have been showing that rest and relaxation, 


\section{SERVICE QUALITY IMPROVEMENT FOR SENIOR}

facilities, activities and safety, and then also cleanliness are important factors that motivate senior tourists to travel and stay in hotels. Service providers need to satisfy senior consumers' needs, values and concerns.

These research findings could be beneficial for service providers working in the hotel industry (also known as hospitality). The hotel staff can also use these results to improve their service efficiency, especially knowledge and skills to perform their work correctly and accurately. Private and government agencies (e.g., various institutes of skills' development, universities and colleges) can use this information derived from the hotel managers' perceptions to develop knowledge and skills of workers so that to match the requirements of the today's hotel industry.

On a final note, it would be also important to mention that the results of this research may not be easily generalizable because the data used here are limited to the hotel and resort managers in Nakhon Ratchasima province of Thailand. Further studies in similar areas are required to provide more information regarding the perceptions of the hotels and resorts managers.

\section{References:}

Alén, E., Domínguez, T. \& Losada, N. (2012). New opportunities for the tourism market: Senior tourism and accessible tourism. Visions for global tourism industry: Creating and sustaining competitive strategies, 139-166.

Bengtsson, M. (2016). How to plan and perform a qualitative study using content analysis. Nursing Plus Open, 2, 8-14.

Cleaver, M., Green, C. \& Muller, T.E., (2000). Using consumer behavior research to understand the baby boomer tourist. Journal of Hospitality \& Tourism Research, 24(2): 274-287.

Hsu, C., Cai L. \& Wong, K., (2007). A model of senior tourism motivations - Anecdotes from Beijing and Shanghai. Tourism Management, 28, 1262-1273.

Jang, S. \& Wu, C. (2006). Seniors' travel motivation and the influential factors: An examination of Taiwanese seniors. Tourism Management, 27, 306-316.

Luk, S. T. \& Layton, R. (2002). Perception Gaps in customer expectations: Managers versus service providers and customers. Service Industries Journal, 22(2), 109-128.

National Statistical Office (2019). Report on the 2017 Survey of the Older Persons in Thailand. Retrieved on 1.02.2019 from: http://www.nso.go.th/sites/2014en/Pages/survey/Social/ Demographic, Population and Housing/The-Survey-Of-Elderly-In-Thailand.aspx

Nella, A. \& Christou, A. (2016). Extending tourism marketing: Implications for targeting the senior tourists' segment. Journal of Tourism, Heritage \& Services Marketing, 2(2), 36-42.

Nikitina, O. \& Vorontsova, G. (2015). Aging population and tourism: socially determined model of consumer behavior in the "senior tourism" segment. Procedia - Social and Behavioral Sciences, 214, 845-851.

Parasuraman, A., Berry, L. L. \& Zeithaml, V.A. (1990). Delivering quality service: Balancing customer perceptions and expectations. New York: The Free Press.

Sangpikul, A. (2008). Travel motivations of Japanese senior travellers to Thailand. International Journal of Tourism Research, 10, 81-94. 
Thammasane, S. (2012). Model of Service Business Management for Older Persons in Thailand. FEU Academic Review, 6(1), 88-99.

Thanakitputimed, P. (2016). Assessment of Service Quality of 4 Star Hotels at 4 Beaches in Pattaya City, using the Application of SERVQUAL Model. The 7th Hatyai National and International Conference.

Tourism Authority of Thailand (2019). Nakhon Ratchasima. Retrieved from: https://www.tourismthailand.org/Destinations/Provinces/Nakhon Ratchasima/580

Tsang, N. \& Qu, H. (2000). Service quality in China's hotel industry: a perspective from tourists and hotel managers. International Journal of Contemporary Hospitality Management, 12(5), 316326.

Viwatkamolwat, N., Boonpalit, A. \& Keonil, N. (2017). Study of Factors Affecting Longevity for Elderly Lodging Design. Veridian E-Journal, Silpakorn University, 10(3), 2763-2774.

Paper submitted

Paper accepted for publishing

Paper published online
19 July 2020

22 September 2020

30 November 2020 